\title{
A Retrospective Study on Bovine Fascioliasis in Veterinary Regional Laboratories in Peninsular Malaysia
}

\author{
J. Nur Alia Diyana, ${ }^{1}$ I. H. Lokman, ${ }^{1}$ S. H. Nur Fazila, ${ }^{1}$ H. Latiffah, ${ }^{1}$ E. B. Ibitoye $\mathbb{C D}^{1,2}$ \\ H. Noor Hazfalinda, ${ }^{3}$ P. Chandrawathani, ${ }^{4}$ Kamaludeen Juriah, ${ }^{5}$ and M. I. Nur Mahiza $\left(^{1}\right.$ \\ ${ }^{1}$ Faculty of Veterinary Medicine, Universiti Putra Malaysia, 43400, Serdang, Selangor, Malaysia \\ ${ }^{2}$ Faculty of Veterinary Medicine, Usmanu Danfodiyo University, P.M.B 2346, Sokoto, Nigeria \\ ${ }^{3}$ Faculty of Health Sciences, Universiti Kebangsaan Malaysia, 43600 UKM Bangi, Selangor, Malaysia \\ ${ }^{4}$ Research and Innovation, Department of Veterinary Services, 62624 Putrajaya, Malaysia \\ ${ }^{5}$ Faculty of Agriculture and Food, Universiti Putra Malaysia Bintulu Sarawak, 97008 Sarawak, Malaysia
}

Correspondence should be addressed to M. I. Nur Mahiza; nurmahiza@upm.edu.my

Received 26 March 2019; Accepted 10 June 2019; Published 1 July 2019

Academic Editor: Bernard Marchand

Copyright (C) 2019 J. Nur Alia Diyana et al. This is an open access article distributed under the Creative Commons Attribution License, which permits unrestricted use, distribution, and reproduction in any medium, provided the original work is properly cited.

\begin{abstract}
This is a retrospective study on bovine fascioliasis infection on cattle in Peninsular Malaysia, spanning from January 2007 to December 2017. Cattle were diagnosed with Fasciola based on the fecal examination and the results were reported to the Veterinary Regional Laboratories in Peninsular Malaysia. These records were analysed for the occurrence of bovine fascioliasis within that 11-year period. Records of annual diagnostic cases from five major Veterinary Regional Laboratories were examined: Bukit Tengah, Pulau Pinang (north); Kuantan, Pahang (east); Johor Bahru, Johor (south); Sepang, Selangor (west); and Kota Bharu, Kelantan (east). A positive fascioliasis infestation was calculated based on a number of positively infected cattle with Fasciola from a number of cattle examined. A total of 1988 cattle were examined during this period and 35 (1.76\%) cattle were reported to be positive for bovine fascioliasis. Parasite infection was the highest at Bukit Tengah region (5.55\%) where 19 cases were positive from 342 reported cases while, at Kuantan (4.96\%), 15 positive cases were reported, unlike Johor Bahru (0.09\%), with only 1 positive case from 1136 cattle examined. Sepang and Kelantan had no positive cases. These results showed that bovine fascioliasis was generally prevalent in the northern and southeast parts of the Peninsular Malaysia; however, there was no significant relationship between the region and the occurrence of fascioliasis.
\end{abstract}

\section{Introduction}

Livestock is one of the rapidly evolving sectors in agriculture, offering potential opportunities for economic growth and alleviation of poverty among rural dwellers, by generating market opportunities for the poor livestock-dependent and enhancing food security and nutrition [1]. However, parasitic diseases, such as fascioliasis, are considered major obstacles for the efficient production and maintenance of health as well as food safety of animal origin. They can cause significant economic loss in countries with livestock industry as an important segment of the agricultural products $[2,3]$. Fascioliasis is a parasitic disease caused by liver flukes of the Fasciola genus and is of importance for both farm animals (especially ruminants) and humans $[4,5]$. Fascioliasis infections have increased worldwide in the last decade and it is reported that 2.5 million people in 61 countries were infected by these parasites in addition to over 180 million people being at risk [6]. This disease has been considered a worldwide problem as it was reported in both developed and developing countries [4]. Animal fascioliasis continued to evolve due to unregulated movements of infected animals from region to region, where Fasciola spp. had been endemic for several years. Besides, moisture and the optimal temperature above $10^{\circ} \mathrm{C}$ found in these regions are essential aspects for the growth of miracidia, the reproduction of the snails (the intermediate host-Lymnaea auricularia rubiginosa), and larval development $[2,7]$. Cattle were most likely infected 


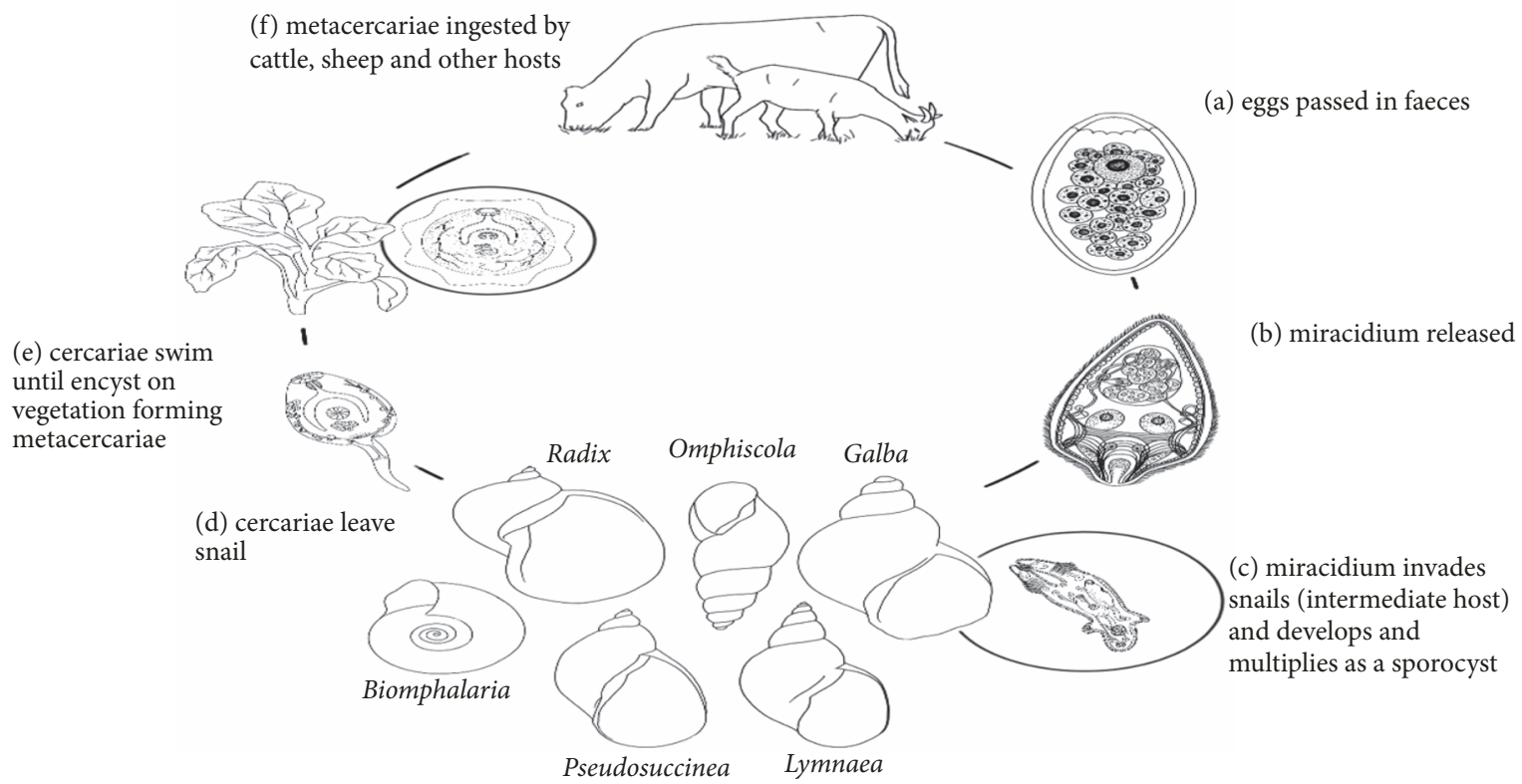

Figure 1: The life cycle of Fasciola in ruminants.

with fascioliasis when they graze on grasses near the lake or river where metacercariae are attached on the grass [8]. In India, the prevalence of this disease is high in areas surrounding dams or large ponds where Lymnaea auricularia rubiginosa, the intermediate host of F. gigantica, is found [9]. The snail acts as the main factor for development of miracidia into metacercariae which is ingested by the cattle [10] [see Figure 1].

Economic losses from fascioliasis in ruminants (goats, sheep, cattle, and buffaloes) are usually due to a drop in livestock production, growth reduction, liver condemnation at slaughter, reduction in draught power, and high usage of anthelmintic [11]. However, the estimation of production and economic loss due to fascioliasis at national and regional level is limited due to lack of accurate estimation of fascioliasis prevalence. Hence, it is essential to have information on the status of parasitic diseases with regard to its magnitude of occurrence, negative production, and economic impact from different parts of the country to establish appropriate strategy for prevention and control of this disease. Therefore, the objective of this study was to determine the occurrence of bovine fascioliasis over time, diagnosed in five major regional veterinary laboratories in Peninsular Malaysia.

\section{Materials and Methods}

This study was carried out using samples submitted to the Regional Veterinary Laboratories (RVL) located in Johor Bahru, Kuantan, Kota Bahru, Sepang, and Bukit Tengah in Peninsular Malaysia. Each RVL receives samples from different states as shown in Table 1. There are several regional laboratories that serve the entire Malaysia and are concentrated in regions of high number of animals. The retrospective data were collected for the period of eleven years from January 2007 to December 2017.
Each laboratory database includes information of the source of the sample, data of submission date, and breed of animals. Records were examined on annual basis with regard to cases of fascioliasis reported in cattle. The occurrence of fascioliasis was calculated as the proportion of positive samples out of the samples that were submitted. The proportion of samples that tested positive by region or by year was computed in a similar way. The significance of association between the occurrence of fascioliasis and a region was evaluated using the logistic regression analysis and quantified by computing the odds ratio. Data were entered, validated, and calculated in Microsoft ${ }^{\circledR}$ Excel 2007 spreadsheet.

\section{Results and Discussion}

A total of $1988 \mathrm{fecal}$ samples were examined during the period of eleven years and $35(1.76 \%)$ of these samples tested positive for fascioliasis. Occurrence of bovine fascioliasis was the highest in Bukit Tengah RVL with 5.55\% (19/342), followed by Kuantan RVL, 4.96\% (15/302). In Johor Bahru RVL, 0.09\% (1/1136) positive cases were reported, while both Sepang and Kota Bahru RVLs did not report any positive samples during the study period (Table 2).

For the annual trend of bovine fascioliasis, the highest occurrence was reported in 2009 (0.40\%), while the lowest proportion of fascioliasis-positive samples was observed in $2014(0.03 \%)$, as shown in Figure 2. On monthly trend of fascioliasis, most numbers of cases were reported in March (eight cases) while the least numbers of bovine fascioliasis cases were reported in May (zero cases) as in Figure 3.

This study reported present status of Fasciola infections in cattle diagnosed in the selected five Regional Veterinary Laboratories from 2007 to 2017. The results of this study suggested that bovine fascioliasis occurred in the study area, 
TABLE 1: Sources of samples to the five Regional Veterinary Laboratories in Peninsular Malaysia.

\begin{tabular}{ccccc}
\hline & & \multicolumn{2}{c}{ Regional Veterinary Laboratories } & \\
& Kuantan & Bukit Tengah & Kota Bahru & Johor Bahru \\
\hline \multirow{3}{*}{ States } & Pahang & Perlis & Terengganu & Johor \\
& Negeri Sembilan & Kedah & Kelantan & Selangor \\
& & Pulau Pinang & & Melaka \\
\hline
\end{tabular}

TABle 2: Prevalence of bovine fascioliasis cases for eleven-year period from five Regional Veterinary Laboratories in Peninsular Malaysia.

\begin{tabular}{lcccc}
\hline RVL & $\begin{array}{c}\text { No. of positive } \\
\text { samples }\end{array}$ & $\begin{array}{c}\text { Total number of } \\
\text { samples submitted }\end{array}$ & Occurrence (\%) & $\begin{array}{r}\text { Odds ratio and 95\% } \\
\text { confidence interval }\end{array}$ \\
\hline Johor Bahru & 1 & 1136 & $0.09 \%$ & NA \\
Kelantan & 0 & 208 & $0.00 \%$ & NA \\
Kuantan & 15 & 302 & $4.96 \%$ & 1 \\
Bukit Tengah & 19 & 342 & $5.55 \%$ & $1.2(0.6,2.3)$ \\
Sepang & 0 & 0 & $0.00 \%$ & NA \\
Total & 35 & 1988 & $1.76 \%$ & \\
\hline
\end{tabular}

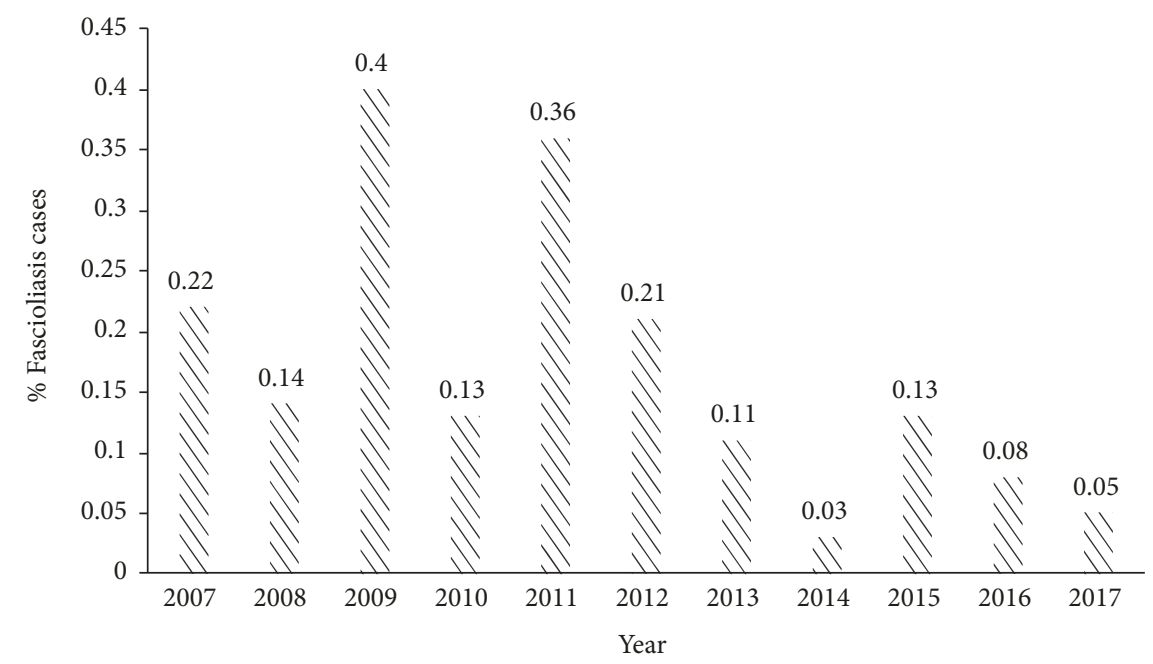

FIGURE 2: Annual trends of fascioliasis cases in five Regional Veterinary Laboratories in Peninsular Malaysia.

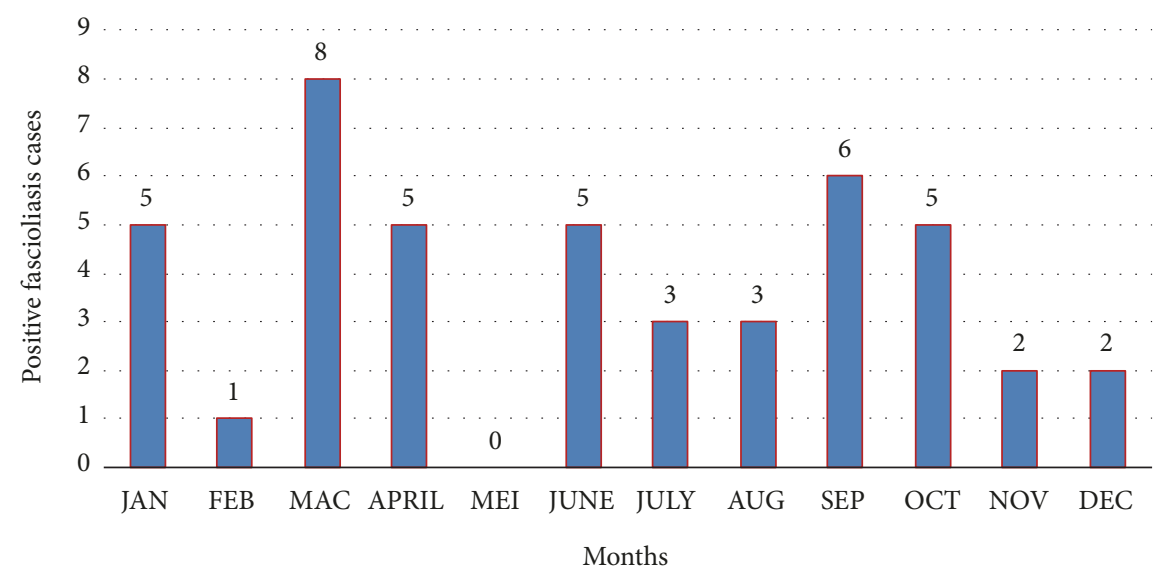

FIGURE 3: Monthly trends of fascioliasis cases in five Regional Veterinary Laboratories in Peninsular Malaysia. 
however in a less severe manner with a prevalence of $1.76 \%$ (35/1988). This result was lower than a prevalence of 3.68\% (385/10462) reported in the liver of cattle slaughtered in 2012-2013 at an abattoir in Kashan region, Center Iran [12], and $28.6 \%$ reported in cattle in Southwest China [13]. In contrast, the prevalence reported in this current study was higher than reported cases in Northeastern Iran, which was $0.71 \%(35 / 4933)$ [14]. These variations in the prevalence of fascioliasis might be attributed to the differences in the climate and ecological settings such as rainfall, seasons, altitude, temperature, origin, and types of animals studied as well as differences in the host immune response to this parasite and the livestock management system. In addition, differences in study design may have also contributed to this varied prevalence. Retrospective data were generated in this current study, while others [12] used a cross-sectional approach.

The current study noted that the highest prevalence of bovine fascioliasis, 5.55\% (19/342), was obtained from Bukit Tengah RVL. A reason for this might be that Bukit Tengah is located in the northern part of the Peninsular Malaysia, which receives samples from Kedah, Penang, and Perlis. The northern parts of Malaysia were known as the rice bowl of the country $[15,16]$, a location favouring the thriving of snail that acts as the intermediate host of fascioliasis. Therefore, it is expected that the numbers of intermediate host were high in this area and the fascioliasis cases were higher as well [17]. This present result agreed with researchers in Vietnam [17], in that high population of intermediate host snails indicated higher risk of fascioliasis. Furthermore, a research conducted in Indonesia [18] also agreed with the current study that the prevalence of F. gigantica infection was high in cattle and buffaloes raised around rice-producing areas where these intermediate host snails thrive.

Monthly trends showed that the highest occurrence for bovine fascioliasis was in March, with eight cases, while no cases of bovine fascioliasis were reported in May. This may be due to the variation in rainfall and number of snail population. A study on the life cycle of F. gigantica in Malawi indicated that the cercariae are released from July to October and cattle are thus exposed to a higher level of infection from August onwards [19]. This probably explains the pattern of distribution noted in this present study.

\section{Conclusion}

It can be concluded that the prevalence of Fasciola infections among cattle in the selected areas is mild, but cattle examined in the Bukit Tengah RVL in the northern part of Malaysia are at higher risk. Nevertheless, herders and policy makers ought to be abreast of this so that practices and policies that will help in maintenance of animals' health are instituted.

\section{Data Availability}

The datasets supporting the conclusions of this article are included within the article. Raw data are available from the authors upon request.

\section{Conflicts of Interest}

The authors declare that they have no conflicts of interest.

\section{Acknowledgments}

The authors would like to thank all Regional Veterinary Laboratories Malaysia staff. This work was supported by the UPM [grant numbers 955910].

\section{References}

[1] T. Robinson and F. Pozzi, "Mapping supply and demand for animal-source foods to 2030," in Animal Production and Health Working Paper, Food and Agriculture Organization (FAO), United Nations, Rome, Italy, 2011.

[2] A. A. Saleha, "Liver fluke disease (fascioliasis): epidemiology, economic impact and public health significance," The Southeast Asian Journal of Tropical Medicine and Public Health, vol. 22, pp. 361-364, 1991.

[3] F. M. D. Aquino, V. E. Soares, G. A. M. Rossi et al., "Prevalence of bovine fascioliasis, areas at risk and ensuing losses in the state of Goiás, Brazil," Revista Brasileira de Parasitologia Veterinária, vol. 27, pp. 123-130, 2018.

[4] S. Mas-Coma, M. A. Valero, and M. D. Bargues, "Fasciola, lymnaeids and human fascioliasis, with a global overview on disease transmission, epidemiology, evolutionary genetics, molecular epidemiology and control," Advances in Parasitology, vol. 69, pp. 41-146, 2009.

[5] World Health Organisation, "Fascioliasis: infection with the "neglected" neglected worms," Neglected Tropical Diseases, 2009, https://www.who.int/neglected_diseases/integrated_ media/integrated_media_fascioliasis/en/.

[6] A. N. Haseeb, A. M. el-Shazly, M. A. Arafa, and A. T. Morsy, "A review on fascioliasis in Egypt," Journal of the Egyption Society of Parasitology, vol. 32, no. 1, pp. 317-354, 2002.

[7] A. K. Mursyidah, S. Khadijah, and N. Rita, "Fasciola and paramphistomum infections in small ruminants (sheep and goat) in terengganu," Malaysian Journal of Veterinary Research.vol 8no. (2, vol. 8, no. 2, pp. 8-12, 2017.

[8] V. Jean-Richard, L. Crump, A. A. Abicho et al., "Prevalence of fasciola gigantica infection in slaughtered animals in southeastern lake chad area in relation to husbandry practices and seasonal water levels," BMC Veterinary Research, vol. 10, p. 81, 2014.

[9] J. A. Kuchai, M. Z. Chishti, M. M. Zaki, S. A. D. M. Rasool, J. Ahmad, and H. Tak, "Some epidemiological aspects of fascioliasis among cattle of ladakh," Global Veterinaria, vol. 7, no. 4, pp. 342-346, 2011.

[10] U.S. Department of Health \& Human Services, Fascioliasis, DPDx - Laboratory Identification of Parasites of Public Health Concern, 2017, https://www.cdc.gov/dpdx/fascioliasis/index .html, 2017.

[11] K. Rosilawati, S. Ramli, and A. R. Saipul Bahari, "Fascioliasis in an adult draught buffalo in Malaysia: a case report," Malaysian Journal of Veterinary Research, vol. 8, no. 1, pp. 169-172, 2017.

[12] H. Khoramian, M. Arbabi, M. M. Osqoi, M. Delavari, H. Hooshyar, and M. Asgari, "Prevalence of ruminants fascioliasis and their economic effects in Kashan, center of Iran," Asian Pacific Journal of Tropical Biomedicine, vol. 4, no. 11, pp. 918922, 2014. 
[13] J.-X. Chen, M.-X. Chen, L. Ai et al., "An outbreak of human fascioliasis gigantica in southwest china," PLoS ONE, vol. 8, no. 8, Article ID e71520, 2013.

[14] A. Oryan, M. Mansourian, M. Moazeni, B. Nikahval, and S. Barband, "Liver distomatosis in cattle, sheep and goats of Northeastern Iran," Global Veterinaria, vol. 6, no. 3, pp. 241-246, 2011.

[15] S. M. Shafie, T. M. I. Mahlia, H. H. Masjuki, and A. AhmadYazid, "A review on electricity generation based on biomass residue in Malaysia," Renewable \& Sustainable Energy Reviews, vol. 16, no. 8, pp. 5879-5889, 2012.

[16] M. U. Azizan and K. Hussin, "Multiple driving forces of paddy land conversion: a lesson from malaysia's rice bowl state," Jurnal Teknologi, vol. 78, no. 1, pp. 39-43, 2016.

[17] N. T. Nguyen, T. C. Le, M. D. C. Vo et al., "High prevalence of cattle fascioliasis in coastal areas of Thua Thien Hue province, Vietnam," Journal of Veterinary Medical Science, vol. 79, no. 6, pp. 1035-1042, 2017.

[18] J. A. R. Roberts, J. A. Copland, and D. B. Copeman, "Control of Bovine Fasciolosis in Indonesia," Epidemiologie et Sante Animale, pp. 31-32, 1997.

[19] S. A. T. Mzembe and M. A. Chaudhry, "The epidemiology of fascioliasis in Malawi part II. Epidemiology in the definitive host," Tropical Animal Health and Production, vol. 13, no. 1, pp. 27-33, 1981 . 


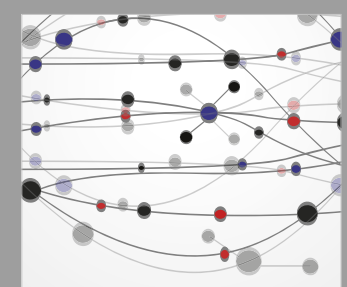

The Scientific World Journal
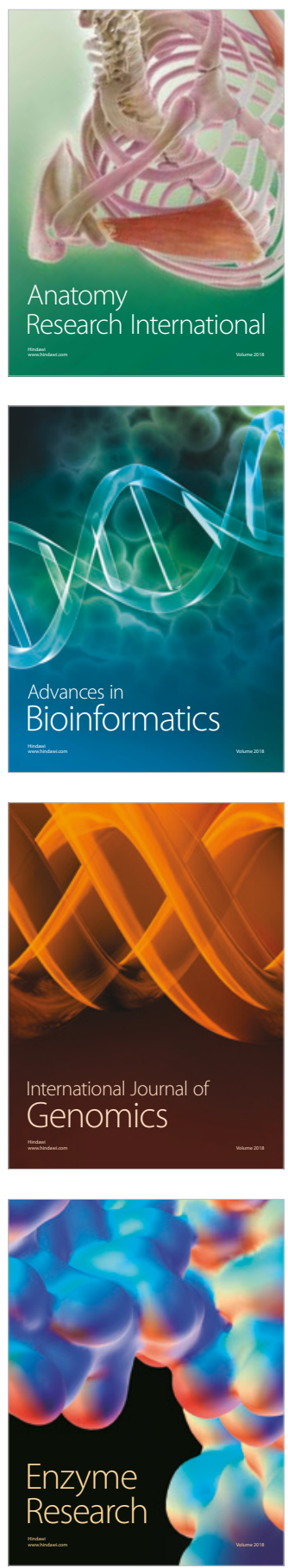
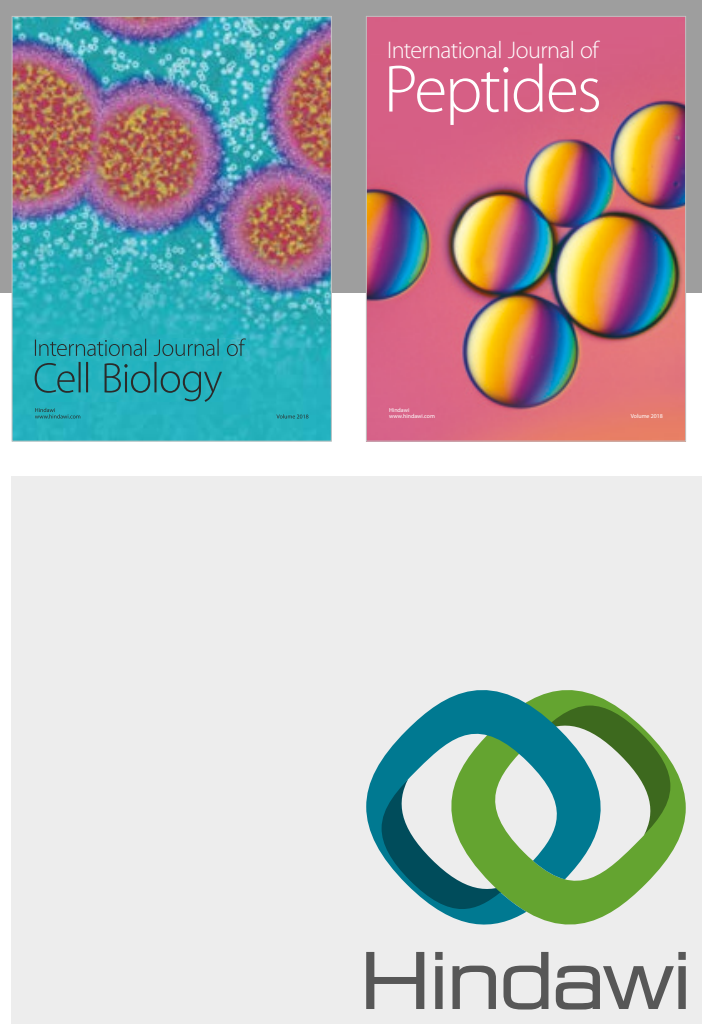

Submit your manuscripts at

www.hindawi.com
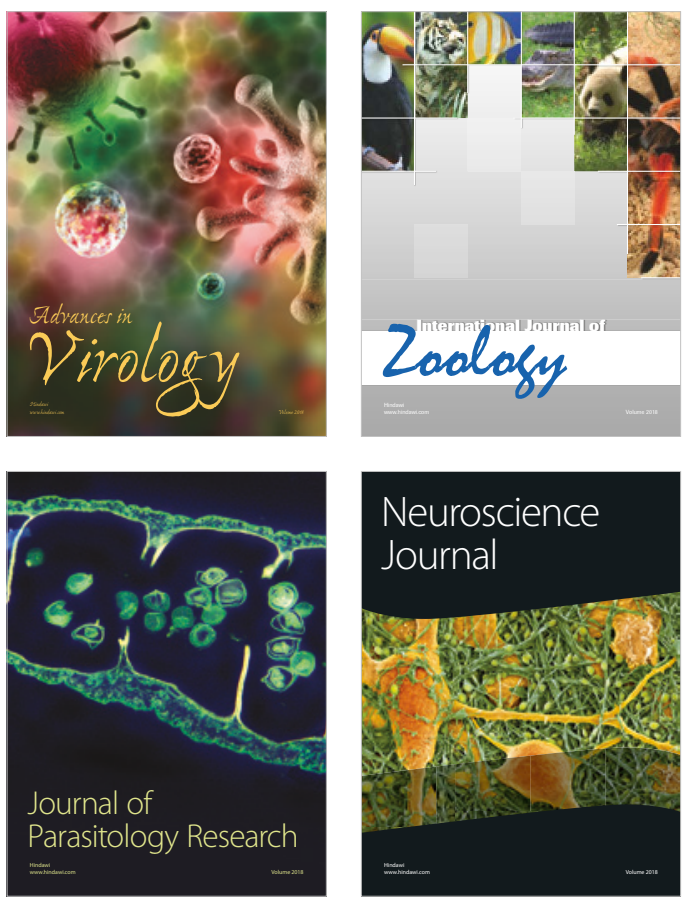
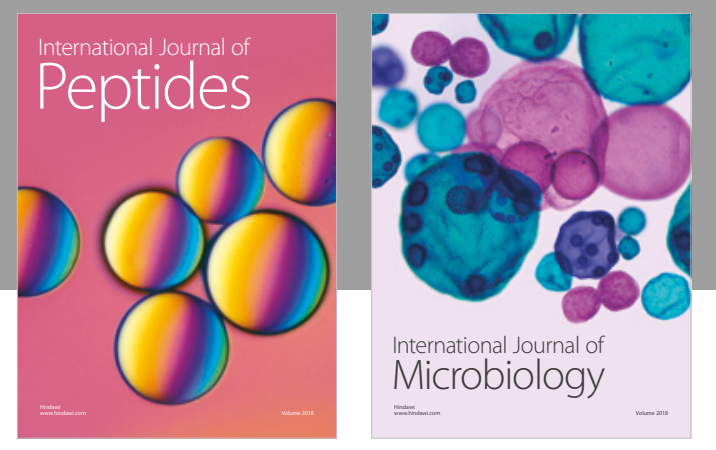

nternational Journal of Microbiology
Journal of
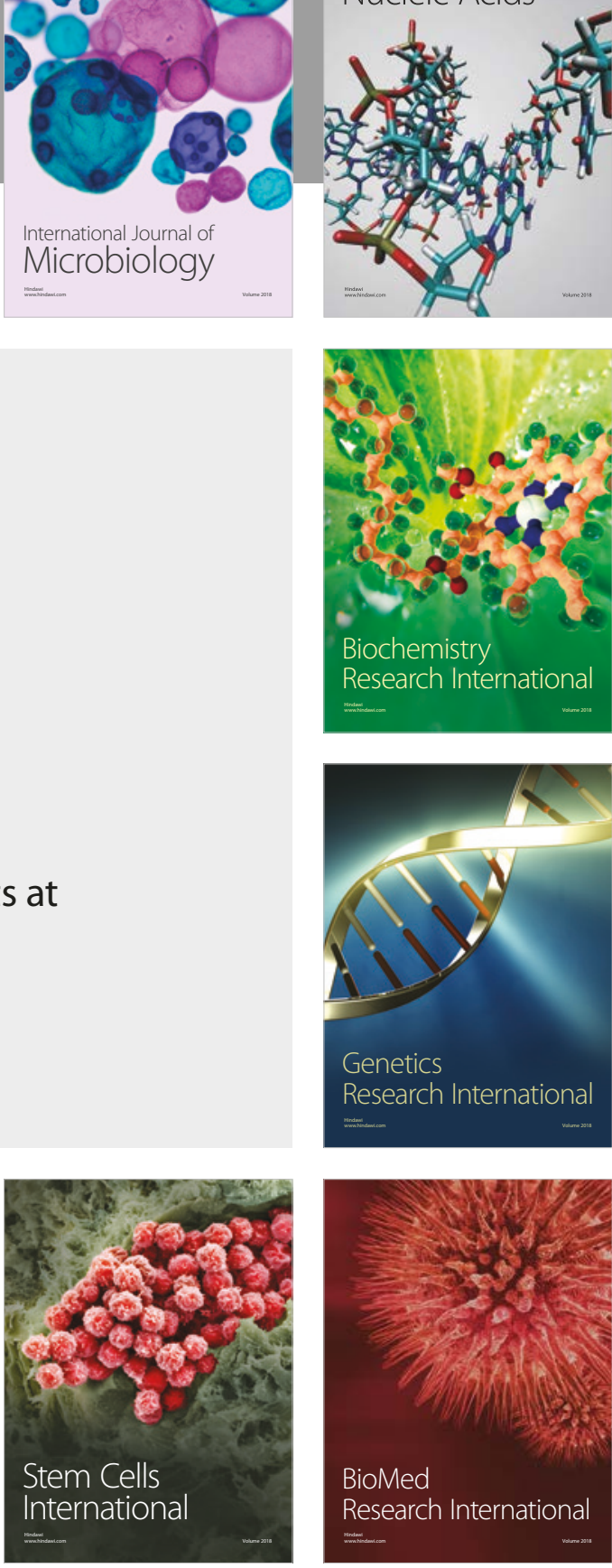
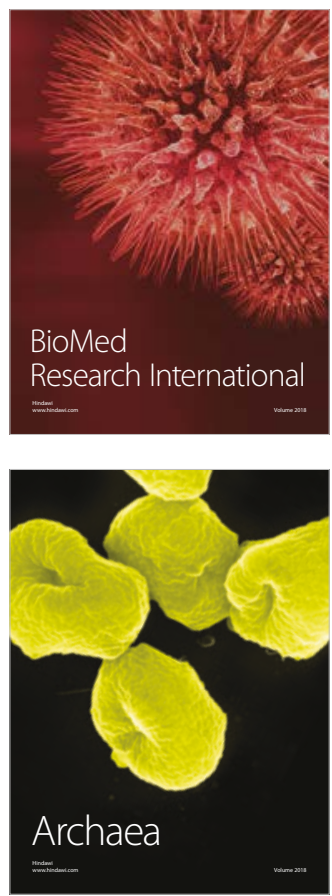